\title{
PAROXYSMAL TACHYCARDIA IN INFANCY
}

\author{
BY \\ JOHN APLEY, BERYL D. CORNER and THOMAS C. GIBSON \\ From the Department of Child Health, University of Bristol, and Bath Royal United Hospital
}

(RECEIVED FOR PUBLICATION MARCH 22, 1955)

There have been many reports of paroxysmal tachycardia as it occurs in adults, some describing it in children, but very few in which infants alone are considered. Yet, though diagnosis in infancy is most urgent, it is then least familiar; there must still be many cases misdiagnosed, for example, as pneumonia. In an outstanding paper Hubbard (1941) first drew attention to the clinical picture of paroxysmal tachycardia in infancy. He described nine personal cases, the largest individual series so far. In 1952 Nadas, Daeschner, Roth and Blumenthal incorporated Hubbard's and other cases, taking infants and children together, and making a total of 41 seen over a period of 20 years at the Boston Children's Hospital. Some valuable conclusions about differences between the two age groups were drawn. In this country, since Poynton and Wyllie (1926) reported a case of 'delirium cordis' in infancy, very few cases have been published (Leys, 1945; Neubauer, 1945; Wright, 1953). We present here a short account of 13 further cases of paroxysmal tachycardia in early infancy.

\section{Clinical Picture}

The case reports are tabulated. Further details are given in the three fatal cases.

General. The child's general condition was always, though variably, affected. He appeared unwell and listless; often he was feverish and restless and sleep was disturbed. Feeding was usually difficult, with unwillingness to feed or inability to continue feeding for more than a short time.

The temperature was raised in four of our cases. In two of these pneumonia was diagnosed, but in the remaining two (Cases 11 and 12) no infectious process was found either clinically or radiologically, and the rise in temperature was presumed to be due to heart failure. Case 12 developed a temperature of $104^{\circ}$ (the highest in the series) which fell to normal in a few hours, at the same time as the heart rate and liver size returned to normal, on treatment only with 'digoxin'.
Respiratory. Superficially the most obvious disturbance appeared to be respiratory, and most infants had been diagnosed as suffering from pneumonia. In 11 of 13 cases respiration was markedly rapid and sometimes laboured, usually with rib recession and activity of accessory muscles of respiration. Moist sounds in the lungs were, however, detected in only four cases, and two of these were considered to be cases with pneumonia in addition to paroxysmal tachycardia. In these two infants radiography of the chest showed definite pneumonic changes. Congestion of the lung fields was suggested radiologically in half the cases.

Alimentary. In three infants vomiting occurred. In one of these the diagnosis of hypertrophic pyloric stenosis had been suggested; another was referred for an opinion as a feeding problem. One infant with pneumonia as well as paroxysmal tachycardia had diarrhoea.

Cardiovascular. In eight infants (including one with pneumonia) slight cyanosis was observed; four of them had an ashen colour, presumably due to associated pallor. Pallor was observed in two other infants who were not cyanosed. Dilatation of the neck veins could be detected in only one case, though it was looked for in all. In 11 cases the liver was greatly enlarged. Scrotal oedema occurred in one infant.

The size of the heart is difficult to ascertain by clinical methods in infants and in only two of our patients was the diagnostic point of cardiac enlargement made; radiologically the heart size was increased in three cases.

Clinical estimation of the heart rate was sometimes only an approximation, because of its extreme rapidity. We found that the rate could be fairly reliably determined by auscultation of the heart; estimations from the radial pulse, arteries in the neck, or superior sagittal sinus through the open fontanelle, were useless and often misleading. It is 
TABLE

13 CASES OF INFANTILE PAROXYSMAL TACHYCARDIA

\begin{tabular}{|c|c|c|c|c|c|c|c|c|}
\hline & Case & Sex & $\underset{\text { (lb. }}{\mathbf{W e}}$ & $\begin{array}{l}\text { rth } \\
\text { ight } \\
\text { oz.) }\end{array}$ & $\begin{array}{c}\text { Age at } \\
\text { First } \\
\text { Attack }\end{array}$ & $\begin{array}{c}\text { Heart Rate } \\
\text { in } \\
\text { Attack }\end{array}$ & Other Signs in Attack & Persistence \\
\hline 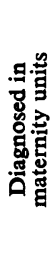 & $\begin{array}{l}\text { No. } 1 \\
\text { (M.B.) } \\
\text { No. } 2 \\
\text { (G.D.) } \\
\text { No. 3 } \\
\text { (T.D.) } \\
\text { No. } 4 \\
\text { (L.R.) } \\
\text { No. 5 } \\
\text { (J.H.) }\end{array}$ & $\begin{array}{l}\mathbf{F} \\
\mathbf{M} \\
\mathbf{F} \\
\mathbf{M}\end{array}$ & $\begin{array}{l}7 \\
5\end{array}$ & $\begin{array}{r}9 \\
10\end{array}$ & $\begin{array}{l}6 \text { days } \\
10 \text { days } \\
(? 3 \text { days) } \\
11 \text { days } \\
11 \text { days } \\
15 \text { days }\end{array}$ & $\begin{array}{l}260 \\
210 \\
280 \\
280 \\
290\end{array}$ & $\begin{array}{l}\text { Pallor, rib recession, rapid } \\
\text { respiration, large liver } \\
\text { Cyanosis, large liver, rapid } \\
\text { respiration } \\
\text { Pallor with cyanosis, large } \\
\text { liver, rapid respiration, } \\
\text { scrotal oedema } \\
\text { Pallor with cyanosis, res- } \\
\text { piratory distress } \\
\text { Pallor, cyanosis, large liver, } \\
\text { rapid respiration }\end{array}$ & $\begin{array}{l}\text { Died } 11 \text { days old; recur- } \\
\text { rences after initial improve- } \\
\text { ment on digitalis } \\
\text { Eight attacks in } 16 \text { months; } \\
\text { none in next two years } \\
\text { Attacks for } 2 \text { weeks; none } \\
\text { in subsequent } 3 \text { years } \\
\text { No further attacks in } 2 \text { years } \\
\text { Occasional recurrences for } \\
3 \text { months; none in next } 9\end{array}$ \\
\hline 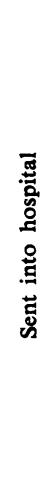 & 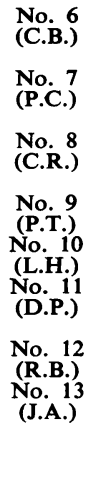 & $\begin{array}{l}\mathbf{M} \\
\mathbf{F} \\
\mathbf{M}\end{array}$ & $\begin{array}{l}7 \\
8 \\
7\end{array}$ & $\begin{array}{r}10 \\
5\end{array}$ & $\begin{array}{l}\text { (? } 4 \text { days) } \\
15 \text { days) } \\
(? 21 \text { days) } \\
24 \text { days } \\
(? 27 \text { days) } \\
34 \text { days } \\
35 \text { days } \\
42 \text { days } \\
115 \text { days } \\
129 \text { days } \\
\text { (Probably } \\
\text { earlier attacks) } \\
165 \text { days }\end{array}$ & $\begin{array}{c}240 \\
280 \\
290 \\
250 \\
240 \\
\text { clinically } \\
250 \\
\\
220 \\
120 \text { clinically } \\
230 \text { by E.C.G. } \\
460 \text { auricular rate by } \\
\text { E.C.G. }\end{array}$ & $\begin{array}{l}\text { Diarrhoea, alternating pulse, } \\
\text { large liver, rapid respiration } \\
\text { (80), pneumonia. Temp. } 103^{\circ} \\
\text { Vomiting, cyanosis, large } \\
\text { liver, rapid respiration, pul- } \\
\text { monary crepitations } \\
\text { Diarrhoea, pallor and cyano- } \\
\text { sis, rapid respiration, large } \\
\text { liver. } \\
\text { Vomiting, large liver, rapid } \\
\text { respiration. Temp. } 99 \cdot 6^{\circ} \\
\text { Vomiting, pallor, neck stiff- } \\
\text { ness, large liver } \\
\text { Cyanosis, rapid respiration, } \\
\text { large liver, large heart. Temp. } \\
\text { 101·2 } 2^{\circ} \\
\text { Cyanosis, fever, large liver, } \\
\text { rapid respiration. Temp. 104 } \\
\text { Not thriving, large heart, pul- } \\
\text { monary crepitations, respira- } \\
\text { tory infection }\end{array}$ & $\begin{array}{l}\text { Died } 17 \text { days old; on digitalis } \\
\text { and antibiotics } 1 \text { day } \\
\text { No recurrence in } 3 \frac{1}{2} \text { years } \\
\text { No further attacks for } 6 \\
\text { months } \\
\text { Several attacks first } 6 \text { months; } \\
\text { then no recurrence in } 1 \frac{1}{2} \text { years } \\
\text { Relapses becoming less fre- } \\
\text { quent during } 6 \text { years } \\
\text { Died } 116 \text { days old; on } \\
\text { 'digitalis' and antibiotics } 1 \text { day } \\
\text { One relapse in a few days, } \\
\text { but no more for } 2 \text { years } \\
\text { A few attacks until } 7 \text { months } \\
\text { old; then no more in next } \\
3 \text { years }\end{array}$ \\
\hline
\end{tabular}

important to note that in one case (No. 6) pulsus alternans occurred at times; pulse estimations were then dangerously inaccurate, since the apparent rate was half the correct figure as obtained by auscultation over the heart. In some cases transient systolic murmurs were heard over the praecordium.

\section{Electrocardiographic Findings}

In 12 of our 13 cases electrocardiograms were recorded during an attack of tachycardia. The rates varied from 210 to 290 . Case 13 was the only certain example of auricular flutter, with an auricular rate of 460 and a $2: 1$ ventricular response (Fig. 1).

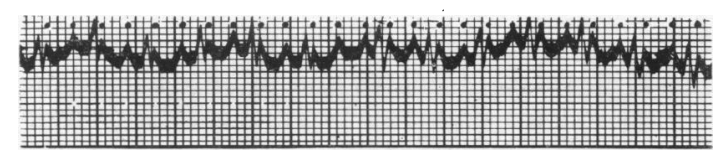

FIG. 1.-Case 13: E.C.G. lead I, showing 2 : 1 flutter with ventricular rate 230 and auricular rate 460 . The auricular complexes are marked with dots.

We could clearly identify only one record as nodal in type (Case 9) with the $P$ wave following the ventricular complex (Fig. 2). The remainder were classified as supraventricular tachycardia. There were no examples of ventricular tachycardia.

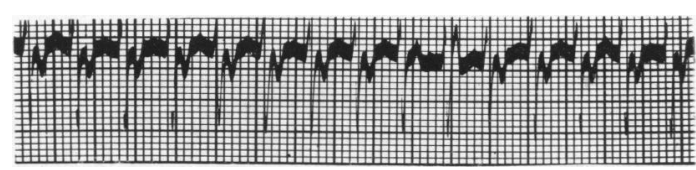

FIG. 2.-Case 9: E.C.G. lead I, illustrating low nodal tachycardia with $\mathbf{P}$ inversion immediately following Q.R.S. One upright $P$ wave is seen, probably of sinus origin.

Electrocardiograms in normal rhythm were available. They were normal for infants of this age group, with one exception; immediately following attacks of paroxysmal tachycardia the $P$ waves were often unusually tall, reaching $6 \mathrm{~mm}$. on one instance (Case 9, lead II). This temporary anomaly has been previously noted by Nadas et al. (1952). In the only patient (Case 10), in whom an attack of tachycardia was not recorded, the electrocardiogram in normal rhythm was typical of the Woolf-Parkinson-White syndrome with short P-R interval and QRS suggesting left bundle branch block due to premature activation of the right ventricle (Fig. 3). In view of the history and typical clinical findings, including the clinical determination of a heart rate of 240 in several attacks, the diagnosis of paroxysmal tachycardia seemed reasonable. In another infant (Case 5) partial right bundle branch block and a shortened P-R interval (0.08 seconds) were recorded 
following an attack. These did not persist and may have represented a transient form of the WoolfParkinson-White syndrome, since in the following electrocardiogram in normal rhythm the P-R interval was $0 \cdot 10$ seconds.

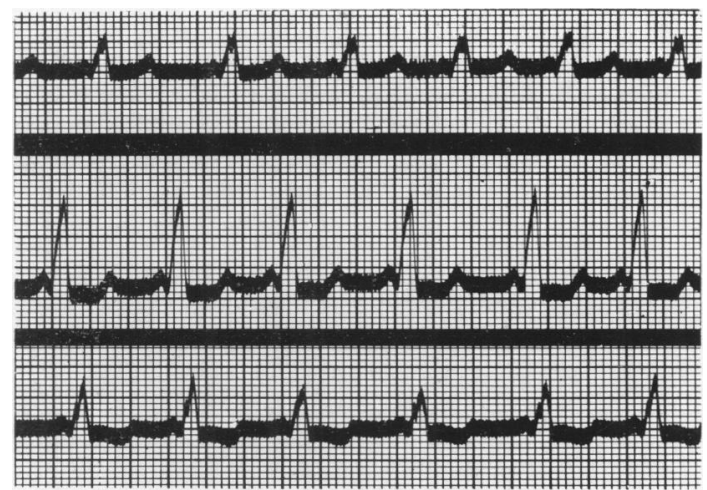

Fig. 3.-Case 10: E.C.G. leads I, II, III showing short P-R interval ( 0.08 seconds) and Q.R.S. suggesting left bundle branch block (Woolf-Parkinson-White syndrome).

\section{Fatal Cases}

There were three deaths in our series, and the clinical and necropsy findings are given in some detail.

Case 1. M.B., a girl, was born after a normal pregnancy and labour (birth weight $5 \mathrm{lb} .15 \mathrm{oz}$.). On the sixth day she refused feeds and abnormal respiration was observed, periods of hyperpnoea alternating with apnoea.

On examination she was a pale, limp child with cold extremities. The temperature was $98 \cdot 0^{\circ} \mathrm{F}$., the pulse rate 260 per minute. Respirations were irregular and rapid. Rib recession occurred, though there were no abnormal signs in the lungs. The cardiovascular system appeared normal apart from tachycardia. There was no hepatic enlargement or oedema.

An electrocardiogram showed $1: 1$ auricular tachycardia (rate 260), and no abnormality was found on a radiograph of the chest.

A diagnosis of paroxysmal tachycardia was made and 'digoxin', 0.025 mg., was given six hourly intramuscularly. The child was nursed in an oxygen tent. Within 24 hours the heart rate fell to 180 per minute and she improved considerably. The following day she appeared to relapse, becoming cyanosed and feeble, with evidence of respiratory distress. On the tenth day she again improved, heart and respiration rates were regular, and 'digoxin' was discontinued. On the eleventh day she suddenly became deeply cyanosed, cold and feeble with rapid irregular respirations and an extremely rapid and feeble heart beat. 'Digoxin' and oxygen were again administered, but six hours later she died.
NeCropsy Report. Dr. N. J. Brown reported as follows:

Slight generalized oedema was present with excess fluid in the abdominal and pleural cavities. There was a small amount of excess fluid in the pericardium. The heart did not appear enlarged. The right auricle and the ventricles were a little dilated; the left auricle and all valves were normal. The left ventricle showed an area of slightly thickened and opaque endocardium, measuring $9 \times 5 \mathrm{~mm}$., immediately below the aortic valve on the upper part of the posterior wall. At the lower end of this patch there was a small group of subendothelial petechial haemorrhages. A large haemorrhage, $18 \times 2 \mathrm{~mm}$., was found in the upper part of the interventricular septum, continuous with the subendocardial haemorrhages. Another small haemorrhage, $3 \mathrm{~mm}$. in diameter, was visible beneath the epicardium in the immediate vicinity of the sino-auricular node on the lateral aspect of the junction of the superior vena cava with the right auricle.

The lungs showed patchy collapse but no infection. The liver (weight $137 \mathrm{~g}$.) and the spleen (weight $17 \mathrm{~g}$.) both showed acute venous congestion. There were no other significant findings.

Histology of the Heart. The endocardium was slightly thickened and showed an increase in elastic tissue (Fig. 4). The myocardium showed a diffuse and

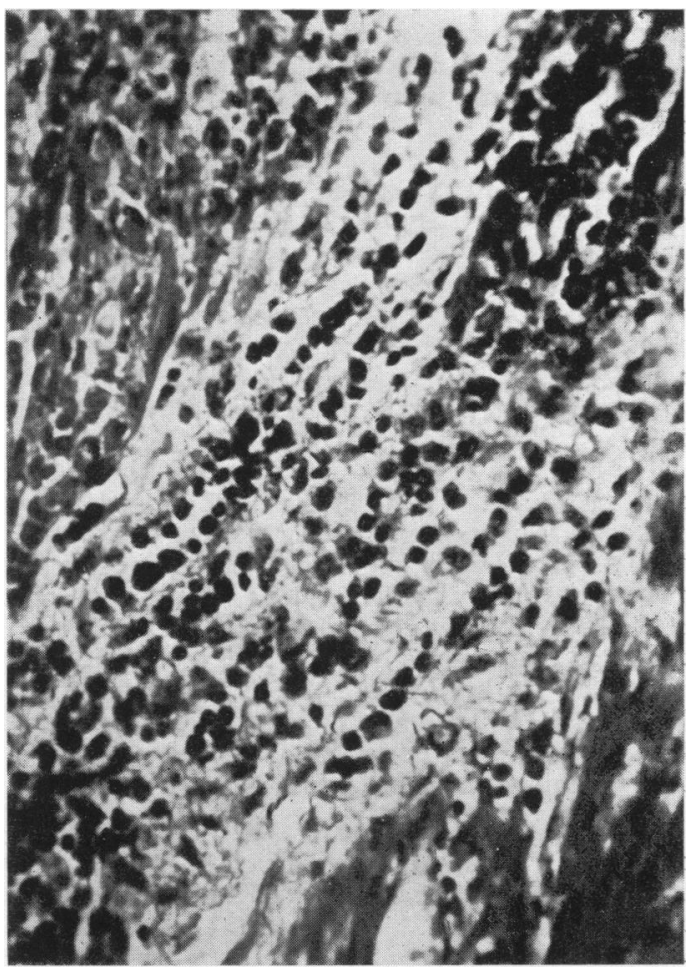

Fig. 4.-Case 1: photomicrograph of myocardium $(\times 400$ haematoxylin and eosin), showing intense interstitial infiltration by mononuclear cells. 
intense infiltration by large mononuclear cells and a few polymorphs; this reaction was not particularly noticeable round blood vessels. There were some strands of fibrous tissue traversing the myocardium but the muscle fibres themselves were normal.

Comment. This appeared to be a case of acute interstitial myocarditis. It is true that there was perhaps a little increase in fibrous and elastic tissue in the endocardium, but not to anything like the extent that is seen in typical fibro-elastosis. On the other hand myocarditis, although patchy, was well marked and not merely a reaction to haemorrhage. There was no evidence of toxoplasmosis nor could inclusion bodies be seen in the heart or other organs.

Case 6. C.B., a girl, was born after a normal pregnancy and labour (birth weight $8 \mathrm{lb} .4 \mathrm{oz}$.). On the fourth day there had been dyspnoea and grunting respirations. On the fifteenth day she was noted to be pale and cold, having refused feeds and passed green slimy stools. Respirations were stertorous, the temperature $97 \cdot 4^{\circ} \mathrm{F}$. She was treated with penicillin and a sulphonamide mixture. During the next two days the temperature rose to $103^{\circ} \mathrm{F}$. and the respirations to 80 .

On examination there were signs of consolidation at the right base and it was noted that the heart rate was unduly rapid at 240 . At times the pulse seemed to halve its rate because alternate beats felt softer, but auscultation gave the true rate. The liver was palpable two fingerbreadths below the costal margin.

An electrocardiogram showed $1: 1$ auricular tachycardia, rate 240.

A radiograph of the chest showed cardiac enlargement and possible hilar congestion. There was pneumonitis in the right lower zone and a small left pleural effusion.

A diagnosis of paroxysmal tachycardia complicating pneumonia was made. 'Digoxin', $0.05 \mathrm{mg}$., was given intramuscularly and repeated in five hours. No improvement took place and she died within seven and a half hours.

NeCropsy REPORT. Dr. H. J. Heathcote reported as follows:

The body was that of a well covered infant, with the umbilicus healed over. The pleural, pericardial and peritoneal cavities contained a considerable quantity of fluid. There was a small area of partial collapse in the middle lobe of the right lung, with a small amount of pus in the bronchi of the right lower lobe. The lungs were congested and oedematous. The empty weight of the heart was $1 \mathrm{oz}$., and the right auricle was slightly dilated. The vessels, chambers and valves were normal; the foramen ovale was not patent. The liver was slightly enlarged, other abdominal organs normal.

Comment. It is possible that in this case the tachycardia was idiopathic, but in view of the pulmonary and other findings it has been included amongst those associated with infection.

Case 11. D.P., a boy, was born after a normal pregnancy and labour (birth weight $7 \mathrm{lb}$.). At three weeks he had coryza and pyrexia which was treated with sulphonamides. Since then he had gained weight slowly, and he was noted lately to have a pigeon chest. On the day of admission (115th day of life) he started screaming half an hour after the 2 p.m. feed and continued all afternoon. Respiration was noted to be rapid and grunting in quality; he felt hot, had a slight cough and was apathetic. He was admitted to hospital in the evening as a case of respiratory infection.

On examination he was cyanosed, with a temperature (rectal) of $101 \cdot 2^{\circ}$, pulse rate at least 270 and respiratory rate 50 with reversal. The heart was clinically enlarged. The lungs were clear. The liver was enlarged to the umbilicus and later to the right iliac fossa. The ankles were oedematous.

An electrocardiogram showed 1:1 auricular tachycardia, rate 250 .

A diagnosis of paroxysmal tachycardia was made and he was given $0 \cdot 1 \mathrm{mg}$. of 'digoxin' by mouth, and 150,000 units of procaine penicillin intramuscularly. He was nursed in an oxygen tent. There was no improvement and within three hours he died.

NeCropsy Report. Dr. A. J. M. Reese reported as follows:-

There was a small amount of fluid in the abdominal cavity and in both pleural cavities. There were a few petechial haemorrhages on the pericardium. There was a thin layer of fibrin on the visceral pericardium of the ventricles. The heart weighed $115 \mathrm{~g}$.; the right auricle was of normal size with a normal endocardium. The tricupsid valve was normal. The right ventricle was normal in size with a wall of normal thickness and a normal endocardium. The pulmonary valve and artery were normal. The foramen ovale was closed. The left auricle was dilated: the wall was thickened and there was a marked thickening and opacity of the endocardium. The mitral valve was narrowed with a ring $3.6 \mathrm{~cm}$. in circumference. The chordae tendineae were not thickened but were short. The left ventricle was dilated. The wall was greatly hypertrophied and $1 \mathrm{~cm}$. thick. The endocardium was dense and white and all the columnae carneae were white and fibrotic. The thickening extended almost up to to the aortic valve, but this structure was normal. The coronary arteries were normal. The aorta and great veins were normal. The left lung weighed $65 \mathrm{~g}$. and was normal. The right lung weighed $90 \mathrm{~g}$. and was solid and congested; it contained no air except for a few segments at the base. The liver weighed $185 \mathrm{~g}$. and was congested. Otherwise no other abnormality was found.

Histology. Section of the left ventricle showed gross fibro-elastosis spreading from the endocardium into the substance of the muscle. Fine elastic fibres were present deep in the myocardium. A section of the right lung showed severe congestion with blood in the alveolar spaces.

COMment. This was a case of heart failure due to severe fibro-elastosis confined to the left auricle and ventricle. The mitral valve was stenosed. There were no other malformations. 
Treatment

During an Attack. Nadas et al. (1952) have reported a death following bilateral carotid pressure, and we consider that mechanical methods to induce reflex vagal stimulation should not be used, as they are unsatisfactory and potentially dangerous in infants.

Digitalis preparations have been found to be of value (Hubbard, 1941) and 'digoxin' was given in 11 of our cases. The optimum dosage of 'digoxin' approximated to $0.05 \mathrm{mg}$. initially for a $7 \mathrm{lb}$. infant, given either intramuscularly or orally, followed by $0.025 \mathrm{mg}$. six-hourly for the first 24 hours. Subsequently a proportionate maintenance dose should be given. Infants appear to tolerate digitalis well and no important side-effects were noted. It was our impression that 'digoxin' was effective in controlling cardiac failure rather than in terminating the paroxysms. This is of importance since failure has usually developed by the time the infant is seen.

In view of the dangers of cardiac failure, diagnosis and treatment should be attempted as early as possible. We were fortunate in that many of our cases were diagnosed while still in hospital, eight within 24 hours of the onset of symptoms and two within 48 hours. We could not, however, correlate early diagnosis with a quick response to treatment, possibly because diagnosis is likely to be made earlier in the more serious cases for the very fact that in them signs and symptoms quickly become evident.

The value of treatment directed towards terminating the paroxysm is less clear. Reports on the successful use of 'mecholyl' in three cases (Silverman and Werner, 1950; Gibson, 1950) are tempered by failure in five with one death due to cardiac arrest (Nadas et al., 1952). We gave 'prostigmine' and 'amechol' each on one occasion, without effect. Because they are not very effective, and are potentially dangerous, it is questionable whether the cholinergic drugs should be used in infants except as a last resort.

Procaine amide was used in one case (Case 5), $17.5 \mathrm{mg}$. being given intravenously over a period of eight minutes under continuous electrocardiographic control. No change in rate or rhythm was noted. Sher (1953) has, however, given up to $100 \mathrm{mg}$. of procaine amide intravenously to an 8-week-old infant with immediate termination of an attack and no side-effects. Quinidine was not given to our cases, as knowledge of its effects in infancy is limited and there appears to be little evidence on the question of tolerance in this age group. There are, however, reports on its use with good effect (Nadas et al., 1952; Moss and Thompson, 1953). Gold (1950) suggests a dosage of $3 \mathrm{mg}$./lb. body weight every three hours by mouth. The successful use of a pressor amine ,'neosynephrine', has been reported in an older child (Cunningham and Schnitzker, 1950).

It should be noted that, in view of the paroxysmal nature of the condition, it is often difficult to assess the therapeutic efficiency of drugs used to terminate an attack of supraventricular tachycardia. The administration of potentially dangerous drugs to these infants must always be considered in the light of the benign course and prognosis in approximately $80 \%$, both in our series and in Nadas's cases of comparable age.

Other Treatment. Our patients were nursed in oxygen tents during the first 48 hours, because of cyanosis and respiratory distress. Infections were treated with an antibiotic. If sedation seemed necessary to allay restlessness and irritability chloral hydrate was given.

Prophylaxis. Digitalis was used as a prophylactic measure for at least six months following the initial attack in five cases and there were minor recurrences in three. Three patients, followed up during a similar period, to whom no digitalis was given, all had minor relapses during the first six months but not subsequently. We do not feel able to assess accurately the efficacy of this measure in view of the natural history of the condition, but short-time prophylaxis is probably worthwhile.

\section{Discussion}

Paroxysmal supraventricular tachycardia occurring in infants under the age of 6 months gives rise to a recognizable clinical picture.

Aetiology. In our series, as in that reported by Nadas et al. (1952), there was a high proportion of idiopathic cases; we were unable even to suggest a tentative cause for the attacks in nine of 13 infants. Two of our cases were associated with lung infection. Another was an example of acute interstitial myocarditis, an unusual condition in infancy, and corresponding to those cases described originally by Fiedler (1900). Accounts of primary or isolated myocarditis in infants have been given by House (1948), Raeburn (1948) and Lind and Hultquist (1949). Paroxysmal tachycardia is known to occur in this group in addition to other arrhythmias (Wood, 1950), and in our case the necropsy finding of a large haemorrhage in the vicinity of the sinoauricular node was of interest, but we believe it was probably agonal. Kugel and Stoloff (1933) considered that so-called congenital cardiac hyper- 
trophy might be an end-result of acute interstitial myocarditis in infancy, and it is possible that infants suffering from the idiopathic type of paroxysmal supraventricular tachycardia may include examples of this form of myocarditis. We were, however, unable to find evidence of cardiomegaly on following up our idiopathic cases. The remaining case was due to endomyocardial fibro-elastosis, a condition not suspected as the cause of paroxysmal tachycardia during the few hours that the child survived in hospital. The necropsy findings were, however, characteristic. Bonham Carter (1954) has stated that this form of arrhythmia may occur in endomyocardial fibro-elastosis, but we have found no further case in any other series.

Other reported causes of paroxysmal supraventricular tachycardia in infancy have included congenital heart disease, and there were also two cases due to sino-auricular node tumours in the Boston series.

Nadas observed that the condition was far commoner in males, and of his 18 idiopathic cases under the age of 4 months only one, a day-old baby, was female. This male preponderance was not so outstanding in our series; three of nine infants in the idiopathic group were female, and of these two were aged 10 and 11 days respectively. Among 11 reported cases of paroxysmal tachycardia diagnosed antenatally, five were female (Anderson and Adams, 1953); it is possible that in some infants with paroxysmal tachycardia the disorder is perpetuated from ante-natal life, and a higher incidence of girls might then be expected in any series of very young infants.

The onset of the attack took place under the age of 1 month in $58 \%$ of the idiopathic group, i.e., five of nine infants in our series, and 14 of 24 in Nadas's series.

Clinical Diagnosis. A pattern of physical signs was found fairly consistently. Commonly an infant was noted to have attacks of cyanosis or pallor, or a combination of both, associated with collapse and cold extremities. In the very young infant these findings were often erroneously considered to be due to atelectasis or acute respiratory infection, especially when tachypnoea was observed. They are, however, compatible with peripheral vasoconstriction as a compensatory feature of a low cardiac output.

Tachycardia can easily be overlooked unless the heart rate is assessed by auscultatory methods. If tachycardia is found it is, we consider, helpful to take an electrocardiogram to record the heart rate, a procedure which should give rise to no practical difficulty even in the youngest infant.
A physical sign of considerable significance is hepatomegaly, which was present in 11 of our 13 cases. In infants the liver may increase in size rapidly while tachycardia is present, and subside in a remarkably rapid manner when normal rhythm is restored. Other signs of congestion such as a raised jugular venous pressure, basal pulmonary crepitations and oedema are not usually observed or marked in infancy. Syncope, which has been said to be common and related to changes of rhythm with transient ventricular asystole, was not noted in our series.

Electrocardiographic Findings. In all our cases the main disturbance seen in the electrocardiogram was a paroxysmal increase in the rate of auricular discharge, whether designated supraventricular tachycardia, nodal tachycardia or auricular flutter. The work of Evans (1944) and of Prinzmetal, Corday, Brill, Oblath and Kruger (1952) have demonstrated the unity of the underlying disturbances which produce the abnormal electrocardiographic records on which these diagnoses are based, and the generic term 'auricular tachycardia' is preferred to cover all disturbances now known as flutter or tachycardia. We have, however, used the older nomenclature, first, because of a possible clinical differentiation, and, secondly, because it is better known. In our series so-called auricular flutter was rare and only one certain example was found (Case 13). In another infant (Case 11) the standard leads were suggestive of auricular flutter, but no right-sided chest leads were available and it is in these leads that the diagnosis can most readily be made (Evans, 1944). It is fortunate that the differentiation of auricular flutter from supraventricular tachycardia is mainly of academic interest in infants, since the treatment of choice for both forms of arrhythmia is digitalis (Prinzmetal et al., 1952).

Prognosis. Of our 10 surviving infants one has continued under observation only for six months. The remainder have been seen at regular intervals over periods varying from one to six years. After six months had elapsed following the original attack it was quite exceptional for further episodes of tachycardia to occur. This did not, however, apply to the child (Case 10) with the Woolf-ParkinsonWhite syndrome, although her attacks are gradually becoming less frequent. The prognosis therefore improves with age; the danger in early infancy is acute heart failure which may rapidly prove lethal. It is, however, usually amenable to treatment, especially if the condition is recognized early, as it should be at least in maternity units. 
It is possible that some infants who develop paroxysmal tachycardia do not seem ill and the condition is not diagnosed. If this is so the clinical descriptions and prognosis of reported cases deal with a selected group.

\section{Summary}

Thirteen cases of paroxysmal tachycardia in infants are reported. All were supra-ventricular. The characteristic clinical and E.C.G. picture in this age group is described. Nine of our cases were 'idiopathic'; in two there was an associated pulmonary infection, in one there was interstitial myocarditis and in one there was endomyo-cardial fibro-elastosis.

Three patients died, and the necropsy findings are described.

Treatment is mainly that of heart failure, and digitalis was the most useful drug. The prognosis improves with age.

We are indebted to Dr. N. J. Brown, Dr. H. J.
Heathcote and Dr. A. J. M. Reese for the necropsy reports, and to Professor C. Bruce Perry for his valuable criticism and advice.

\section{REFERENCES}

Anderson, R. C. and Adams, F. H. (1953). J. Pediat., 43, 668. Bonham Carter, R. E. (1954). In Recent Advances in Paediatrics, ed. Douglas Gairdner, p. 389. London.

Cunningham, G. C. and Schnitzker, W. F. (1950). J. Pediat. 37, 727.

Evans, W. (1944), Brit. Heart J., 6, 221.

Fiedler, A. (1900). Centralbl. F. inn. Med., 21, 212

Gibson, S. (1950). Med. Clin. $N$. Amer., 34, 217.

Gold, H. (1950). Quinidine in Disorders of the Heart. New York.

House, R. K. (1948). Amer. J. Path., 24, 1235.

Hubbard, J. P. (1941). Amer. J. Dis. Child., 61, 687.

Kugel, M. A. and Stoloff, E. G. (1933). Ibid., 45, 828

Leys, D. (1945). Archives of Disease in Childhood, 20, 44

Lind, J. and Hultquist, G. T. (1949). Amer. Heart J., 38, 123.

Moss, A. J. and Thompson, R. H. (1953). Calif. Med., 79, 51

Nadas, A. S., Daeschner, C. W., Roth, A. and Blumenthal, S. L. (1952). Pediatrics, 9, 167.

Neubauer, C. (1945). Brit. Heart J., 7, 107.

Poynton, F. J. and Wyllie, W. G. (1926). Lancet, 2, 371

Prinzmetal, M., Corday, E., Brill, I. C., Oblath, R. W. and Kruger, H. E. (1952). The Auricular Arrhythmias. Springfield, Illinois.

Raeburn, C (1948), J. Path. Bact, 60, 477.

Sher, N. (1953). Brit. Heart J., 15, 459.

Silverman, J. J. and Werner, M. (1950). J. Pediat., 37, 765

Wood, P. (1950). Diseases of the Heart and Circulation. London.

Wright, T. (1953). Brit. med. J., 1, 25. 